\title{
Detection of Mycobacterium leprae in saliva and the evaluation of oral sensitivity in patients with leprosy
}

\author{
Fernanda Borowsky da Rosa ${ }^{1,2} /+$, Victor Costa de Souza ${ }^{3}$, \\ Tatiana Amaral Pires de Almeida ${ }^{3}$, Valdinete Alves do Nascimento ${ }^{3}$, \\ Felicien Gonçalves Vásquez ${ }^{4}$, Maria da Graça Souza Cunha ${ }^{4}$, Felipe Gomes Naveca ${ }^{1,3}$ \\ ${ }^{1}$ Universidade Federal do Amazonas, Manaus, AM, Brasil \\ ${ }^{2}$ Universidade Nilton Lins, Manaus, AM, Brasil ${ }^{3}$ Instituto Leônidas e Maria Deane-Fiocruz, Manaus, AM, Brasil \\ ${ }^{4}$ Fundação de Dermatologia Tropical e Venereologia Alfredo da Matta, Manaus, AM, Brasil
}

The aim of this study was to investigate sensitivity disorders in the oral cavity related to the presence of Mycobacterium leprae in the saliva of treatment-naïve patients with leprosy in the state of Amazonas, Brazil. A cross-sectional study was conducted involving 45 subjects with leprosy. The subjects were interviewed to evaluate the sensitivity of the oral cavity. For the detection of $\mathrm{M}$. leprae, saliva and slit-skin smear samples were collected. The samples were analysed using a bacteriological index (BI) protocol and the real-time quantitative polymerase chain reaction (qPCR). The results indicated that 15 of the $45(33.3 \%)$ subjects with leprosy showed decreased oral sensitivity, which confirmed the importance of the oral cavity sensitivity evaluation. There was not a direct relationship between the presence of $\mathrm{M}$. leprae in saliva and changes in oral sensitivity. Positive saliva qPCR results from six (31.6\%) of 19 paucibacillary (PB) patients suggested the possibility of a new site for sample collection. Positive results using these diagnostic techniques (BI, slit-skin smear and saliva qPCR) increased to 55.5\%, thus opening the possibility of combining these different techniques to increase the rate of positive diagnoses, especially in PB patients.

Key words: leprosy - sensation disorders - oral cavity - real-time polymerase chain reaction

Leprosy is a chronic infectious disease caused by Mycobacterium leprae, which slowly and insidiously affects the skin, peripheral nerves and mucous membranes (Margarido \& Rivitti 2005). This disease can lead to deformity and disability, with serious social implications.

According to the World Health Organization (WHO), international efforts to control leprosy have resulted in remarkable advances, most notably in a reduction in the number of cases in endemic countries. In spite of this, Brazil (16\%), India (58\%) and Indonesia (9\%) contributed $83 \%$ of the new cases detected in 2011 (WHO 2012). Although Brazil has registered a decrease in new cases, leprosy is still a public health concern for the country. In 2011, 33,955 new cases of leprosy were detected in Brazil (WHO 2012), 586 of which were in the state of Amazonas (AM) (FUAM 2011).

The transmission mechanism for leprosy is not clearly understood, but transmission is thought to occur via intimate and prolonged contact with the patients through nasal and oropharyngeal secretions and/or via skin lesions (D’Abreu et al. 2000, Margarido \& Rivitti

doi: 10.1590/0074-0276108052013006

Financial support: POM/ILMD-FIOCRUZ

VCS has a FAPEAM DCTA fellowship, TAPA has a FIOCRUZ/FAPEAM Tec-Tec fellowship and VAN was the recipient of a FAPEAM PAIC/FIOCRUZ fellowship.

+Corresponding author: feborowsky@hotmail.com

Received 19 October 2012

Accepted 27 May 2013
2005, Pontes et al. 2008). M. leprae has a predilection for Schwann cells surrounding the axons of peripheral nerves, leading to progressive losses of thermal, tactile and pain sensitivities.

In most patients, the lesions and neural manifestations precede cutaneous signs (Margarido \& Rivitti 2005). The cranial nerve most affected by leprosy is the trigeminal nerve (V pair), which is responsible for tactile and thermal sensitivity in the face, the anterior two-thirds of the tongue and the hard and soft palates. The second-most affected nerve is the facial nerve (VII pair), which is responsible for the innervation of facial muscles and taste sensitivity of the anterior two-thirds of the tongue (Margarido \& Rivitti 2005).

Trigeminal nerve impairment in subjects with leprosy has also been detected in a study by Reichart et al. (1982), who noted hypoesthesia and anaesthesia in facial areas innervated by the trigeminal nerve in 29 out of 43 subjects.

Neville et al. (2009) argued that a sensory deficit may affect any branch of the trigeminal nerve in subjects with leprosy, but the maxillary branch is the most affected. A study conducted by Kumar et al. (2006) investigated the involvement of cranial nerves in patients with leprosy and found nine out of $51(18 \%)$ subjects with abnormal sensitivity, with the facial nerve (cranial nerve VII) and trigeminal nerve (cranial nerve V) the most affected. Bigom-Taheri et al. (2012) reported similar results in 17 out of 100 leprosy patients evaluated for facial nerve involvement. Previous studies have identified cranial nerve injuries in patients with leprosy during orofacial sensorimotor exams (Reichart et al. 1982, Kumar et al. 2006, Wani et al. 2009). 
Oral lesions in leprosy develop insidiously and are usually asymptomatic and secondary to nasal impairment. Nevertheless, when symptoms appear, the most common signs of this injury occur in the hard palate, soft palate, uvula, tongue and gums in the anterior maxilla (Neville et al. 2009). Today, oral lesions are not often observed due to earlier diagnosis and the use of multidrug therapy (MDT). However, patients in the early stages of the disease may also show impairment of the oral mucosa without apparent injury (da Costa et al. 2003, de Abreu et al. 2006).

The diagnosis of leprosy is challenging due to its complex immune response that leads to a variety of clinical forms. Within this spectrum of clinical presentations, paucibacillary (PB) patients are of major concern because their titres of leprosy bacilli are low, making detection difficult using conventional laboratory techniques (Martinez et al. 2011).

Multiple studies using nucleic acid amplification tests, which are more sensitive than microscopy, have been used to detect the presence of bacilli in biological samples, including those from the oral cavity (Patrocínio et al. 2005, Phetsuksiri \& Rudeeaneksin 2006, Banerjee et al. 2011). This approach may be of paramount importance for M. leprae detection, mostly in the difficult-to-diagnose cases.

Since the introduction of MDT, very few studies have been conducted that evaluated oral sensitivity in patients with leprosy. Therefore, the aim of this study was to investigate sensation disorders in the oral cavity and the presence of $M$. leprae DNA in the saliva of treatment-naïve patients at a reference centre in Manaus, the capital of AM.

\section{PATIENTS, MATERIALS AND METHODS}

This was an analytical cross-sectional study of 45 treatment-naïve patients with leprosy and 45 patients with other skin diseases as the control group. Both groups attended the Foundation of Tropical Dermatology and Venereology Alfredo da Matta (FUAM), which is a tertiary reference centre for leprosy treatment and research located in Manaus.

Subjects were recruited to participate in this study under spontaneous demand. Inclusion criteria for both groups were people aged over 18 and under 60 years of either gender who agreed to participate in the study. Subjects of indigenous ethnicity, pregnant women and individuals with sequelae of injury in the central nervous system and/or sequelae of head and neck cancer treatment were not included in this study.

The subjects in the case and the control groups were recruited at the same institution (FUAM), which is a reference institution for the diagnosis of leprosy and other dermatological diseases. None of the individuals from the control group had a prior history of leprosy treatment or developed any symptoms until the end of this study. Individuals in this group were diagnosed with allergies, vitiligo, acne or psoriasis.

Initially, all participants were subjected to an interview, followed by an evaluation of inner oral cavity sensitivity when biological samples were collected from the leprosy group. The interviews were conducted using closed questions adapted from questionnaires prepared by Furkim and Silva (1999) apud Villar et al. (2004). The medical data for each patient were collected from the records, including the operational classification of the disease, bacteriological index (BI) results, degree of incapacity (physical incapacity and neural damage) and progression time (time between initial symptoms and evaluation). In the control group, only data regarding the clinical diagnoses were obtained.

During interviews, demographic data, such as the name, address, phone number, birth date, age, skin colour, education, marital status and gender, were collected. Data regarding the sensitivity of the oral cavity were obtained by inquiry: difficulty in noticing the taste of food, difficulty in breathing through the nose, dry mouth, globus pharyngeus, coughing or choking during or before eating, hoarseness, throat clearing or voice disorder during or after eating, nasal reflux of food, weight loss, pneumonia and trouble swallowing.

For this study, a protocol for oral cavity sensitivity evaluation was developed. The choice of regions used to evaluate oral cavity sensitivity (soft palate, hard palate and tongue) was based on the anatomical regions of the oral cavity most often affected by leprosy according to the WHO topographic map for oral lesions in subjects with leprosy created by Scheepers et al. (1993). The oral cavity thermal sensitivity evaluation followed the protocol of the Brazilian Ministry of Health (MS 2002) to estimate the sensitivity in skin lesions.

Tactile sensitivity was first evaluated by touching dry cotton swabs to the dorsum of the tongue and the hard and soft palates. The response was considered normal when the patient perceived and located the region touched (hard palate, soft palate and tongue) and the response was considered disturbed when the patient could not perceive the touch. Secondly, thermal sensitivity was evaluated by tapping on the dorsum of the tongue and on the hard and soft palates (indiscriminately) with cotton swabs soaked in room temperature or warm $\left(45^{\circ} \mathrm{C}\right)$ water. The response was considered normal when the patient felt the temperature of the swab (hot or cold) and the response was considered disturbed when the patient could not distinguish the temperature. Finally, taste sensitivity was evaluated by offering gustatory stimuli for sweet $(12 \% \mathrm{w} / \mathrm{v}$ sucrose in water), salty $(2 \% \mathrm{w} / \mathrm{v} \mathrm{NaCl}$ in water), bitter (Peumus boldus tea) and sour (lemon). The response was considered normal when the patient recognised the correct taste.

Slit-skin smear collection and the BI procedure followed the protocols recommended by the Brazilian Ministry of Health (MS 2010). The biological materials used for polymerase chain reaction (PCR) amplification were gathered directly from samples on the scalpel blade used to collect tissue from the right ear lobe (approximately $5-10 \mu \mathrm{L}$ total) and were transferred to a $1.5-\mathrm{mL}$ microtube containing $200 \mu \mathrm{L}$ of $6 \mathrm{M}$ guanidine isothiocyanate (Promega, Madison, WI, USA).

The methodology employed by Abdalla et al. (2010) was used for saliva collection. Patients were instructed to chew a $1 \mathrm{~cm}$ piece of a previously sterilised latex tube (Auriflex, São Roque, São Paulo, BRA) to stimulate 
the production of saliva. All patients were instructed to swallow the saliva produced during the first $30 \mathrm{sec}$ and to collect the saliva produced for the next $5 \mathrm{~min}$ in a sterile universal collector. A total of $500 \mu \mathrm{L}$ of saliva was collected from each universal collector and aseptically transferred to a $1.5-\mathrm{mL}$ microtube with a micropipette. Another $25 \mu \mathrm{L}$ of saliva was spread on a microscope slide to determine the BI. The microtubes containing the samples were stored at $-70^{\circ} \mathrm{C}$ until DNA extraction.

Total DNA from slit-skin samples was extracted using the DNeasy Blood \& Tissue kit (Qiagen, Valencia, CA, USA), as described by the manufacturer, with some modifications. The slit-skin sample in $200 \mu \mathrm{L}$ of guanidine was processed following the manufacturer's protocol beginning at step 6 . The same kit was used for the saliva samples $(250 \mu \mathrm{L})$, but the standard manufacturer's instructions were followed. The extracted DNA was quantified in a microvolume spectrophotometer ASP3700 (ACTGene, Piscataway, NJ, USA).

A quantitative PCR (qPCR) protocol was performed for $M$. leprae DNA detection using a set of primers targeting the $85 \mathrm{AC}$ intergenic region as described by Martinez et al. (2006). This protocol was originally established for conventional PCR and was adapted for real-time detection in this study using GoTaq qPCR master mix (Promega, Madison, WI, USA). The amplification reactions were performed as follows: $2.0 \mu \mathrm{L}$ of a $5.0 \mu \mathrm{M}$ mix containing the $85 \mathrm{AC}$ forward and reverse primers, $10.0 \mu \mathrm{L}$ of $2 \mathrm{X}$ GoTaq qPCR master mix, $5.8 \mu \mathrm{L}$ of ultrapure water, $0.2 \mu \mathrm{L}$ of $100 \mathrm{X}$ carboxy-X-rhodamine and $2.0 \mu \mathrm{L}$ of the DNA sample in a final reaction volume of $20.0 \mu \mathrm{L}$.

In each set of qPCR samples, three non-template controls were included as follows: a "blank" control containing the qPCR Mix and primers only, a negative control containing human DNA from a healthy person and a positive control from a multibacillary (MB) patient slit-skin smear confirmed by DNA sequencing.

The cycling program consisted of an initial denaturation at $95^{\circ} \mathrm{C}$ for $10 \mathrm{~min}$ followed by eight cycles of denaturation at $95^{\circ} \mathrm{C}$ for $15 \mathrm{~s}$, annealing at a touchdown procedure starting at $72^{\circ} \mathrm{C}$ and decreasing $1^{\circ} \mathrm{C}$ per cycle for 30 $\mathrm{s}$ and an extension step at $72^{\circ} \mathrm{C}$ for $30 \mathrm{~s}$. An additional 40 cycles of denaturing at $95^{\circ} \mathrm{C}$ for $30 \mathrm{~s}$, annealing at $64^{\circ} \mathrm{C}$ for $30 \mathrm{~s}$ and extension at $72^{\circ} \mathrm{C}$ for $30 \mathrm{~s}$ were performed after the touchdown phase. A melt-curve analysis was included at the end of each experiment using the default parameters (StepOnePlus, Applied Biosystems, Foster City, CA, USA). The samples were defined as positive if they had a cycle threshold value less than 36 and a Tm value of $90^{\circ} \mathrm{C}\left( \pm 0.5^{\circ} \mathrm{C}\right)$. To validate the results, the negative controls described above should test negative for the target. The samples were analysed in duplicate to ensure consistency in results.

The data were analysed using descriptive statistics and quantitative variables were described using means and standard deviations. The categorical data measuring abnormal sensitivity in the oral cavity were analysed using a two-tailed Fisher's exact test due to small counts $(<50)$. All statistical analyses were conducted using GraphPad Prism 6 software (GraphPad Software, Inc, La Solla, CA, USA).
The level of agreement between the bacilloscopy of the slit-skin smear and qPCR of the slit-skin smear or saliva was calculated using Cohen's kappa test (k) for unweighted proportions (Cohen 1960). The index was characterised as weak $(0.00-0.20)$, low $(0.21-0.40)$, medium (0.41-0.60), good (0.61-0.80) and excellent (0.811.00 ), according to the standards proposed by Landis and Koch (1977).

This research followed the guidelines of Resolution 196/96 of the National Health Council and was approved by the Ethical Research Committee (-015/2010-ERC/ FUAM). All patients gave written informed consent.

\section{RESULTS}

During the study period, 87 subjects with suspected leprosy were interviewed. Among these, 24 subjects did not confirm the initial diagnosis, 12 subjects did not return to complete the evaluation, three subjects did not participate in the study due to meeting the exclusion criteria and three subjects refused to participate. Thus, 45 subjects with leprosy were enrolled and 45 subjects diagnosed with other dermatoses were invited to participate as the control group.

Of the 45 subjects with leprosy, 34 were male $(75.6 \%)$ and 11 were female $(24.4 \%)$. In the control group, the opposite trend occurred, with the majority being female $(28 ; 62.8 \%)$. The mean ages of the subjects in the leprosy group and the control group were similar: 36.7 years and 36.8 years, respectively.

The education level was significantly lower in the leprosy group, where only 17 subjects (37.8\%) had completed the elementary level. However, 29 subjects (64.4\%) in the control group had completed elementary school (Fisher's exact test two-tailed $\mathrm{p}=0.0199$ ). A brown skin colour was the most prevalent, describing $35(77.8 \%)$ and $32(71.1 \%)$ subjects in the leprosy and control groups, respectively. The majority of the patients with leprosy were operationally classified as MB (58\%).

The measurements of oral sensitivity revealed that 15 subjects (9 MB and $6 \mathrm{~PB}$ ) had at least one disturbed variable. A statistically significant difference was identified regarding the alteration of thermal sensitivity in subjects with leprosy compared to the control group (Fisher's exact test two-tailed $p=0.005$ ). Four subjects with leprosy exhibited changes in thermal and taste sensitivities. Three (6.7\%) isolated cases of disturbed gustatory sensitivity were observed in the control group. There was also a significant relationship between the change in tactile sensitivity and a positive slit-skin smear sample BI (Fisher's exact test two-tailed $\mathrm{p}=0.015)$ (Table I).

M. leprae DNA was detected in the saliva of $16(35.5 \%)$ of the 45 patients with leprosy. The operational classification and saliva qPCR results revealed that $10(38.5 \%)$ of the $26 \mathrm{MB}$ patients and six (31.6\%) of the $19 \mathrm{~PB}$ patients were positive for M. leprae DNA. With respect to the operational classification and slit-skin smear qPCR positivity, $10(38.5 \%)$ of the $26 \mathrm{MB}$ patients and three (15.8\%) of the 19 PB patients were positive (Table II).

When the three laboratory diagnosis protocols were analysed separately, the saliva qPCR technique was found to have the highest positivity (16/45), followed by 
the slit-skin smear qPCR (13/45) and the slit-skin smear BI (12/45) techniques. A separate analysis revealed that of the $26 \mathrm{MB}$ patients, $12(46.2 \%)$ were positive according to the BI test, $10(38.5 \%)$ were positive according to the saliva qPCR test and $10(38.5 \%)$ were positive according to the slit-skin smear qPCR test. Of the $19 \mathrm{~PB}$ patients, six (31.6\%) were positive according to the saliva qPCR test and three (15.8\%) were positive according to the slit-skin smear qPCR test. None were positive according to the slit-skin smear BI test. When the results of the three approaches were combined, one sample was positive only in the BI test, eight samples were positive only in the saliva qPCR test and three samples were positive only in the slit-skin smear qPCR test.

Of the 10 positive samples in the saliva qPCR test, eight ( $3 \mathrm{MB}$ and $5 \mathrm{~PB}$ ) were found to be positive with this technique only. The best agreement was reached between the BI test and the slit-skin smear qPCR $(\mathrm{k}=0.50)$ (Table III).

In this study, an association between M. leprae in saliva and oral sensitivity alterations was not statistically supported. Among those patients with abnormalities in oral sensitivity, only three $(18.8 \%)$ had qPCR-detectable bacilli DNA in the saliva and only one was positive in the saliva with the BI test.

\section{DISCUSSION}

One of the key results of this study is that patients with leprosy were significantly more likely to have altered thermal sensitivity of the oral cavity than the control group. This finding agrees with the study of Margarido and Rivitti (2005) that reported a decrease in thermal sensitivity as one of the early symptoms of leprosy.

It is interesting to note that eight out of the 12 cases with disturbed thermal sensitivity of the oral cavity identified in this study were in the first year of the disease progression (data not shown). Furthermore, half of those patients were $\mathrm{PB}$, which are generally more difficult to diagnose. Thus, the results indicate that evaluation of oral sensitivity could serve as a complementary test during the physical examination of suspected leprosy cases.

With regard to the other sensitivity disorders in the oral cavity evaluated in this study, four leprosy patients showed concurrent alteration in thermal and gustatory sensitivity. A similar study conducted by Soni and Chatterji (1981) focusing on taste disorders in leprosy patients showed that 12 out of $30(40 \%)$ subjects had some alteration that was related to the disease severity. However, we were unable to observe any relationship with disease severity because two out of the four patients were PB.

In this study, changes in tactile sensitivity only were observed in three MB patients who were tested subjectively, making it impossible to measure the degree of commitment (hypoesthesia or anaesthesia). According to Margarido and Rivitti (2005), tactile sensitivity is the last sense to be compromised; it is observed only as hypoesthesia in the early disease phase in MB patients, but might progress to anaesthesia in the later stages of leprosy.

Overall, 15 subjects with altered sensitivity in the oral cavity were observed in this study; of these, nine $(60 \%)$ were classified as MB. This finding is in agreement with previous studies in which most of subjects affected with lesions in the oral cavity were classified as MB patients (Scheepers et al. 1993, Bigom-Taheri et al. 2012).

Surprisingly, the qPCR method did not show better positivity than the bacilloscopy of the slit-skin smear (Table III), which may be attributed to the difficulty of DNA extraction from M. leprae. The literature indicates that variations in the positivity of PCR results may be due to the use of different primers, amplicon sizes and amplification protocols (Goulart \& Goulart 2008), thus highlighting the need for standardisation of qPCR for leprosy detection. Although the results of the slit-skin qPCR were not as sensitive as expected in MB patients, this methodology detected M. leprae DNA in three out of 19 PB cases.

TABLE I

Relationship between the sensitivity variable and studied groups

\begin{tabular}{|c|c|c|c|c|c|c|}
\hline \multirow[b]{3}{*}{ Variable } & \multicolumn{4}{|c|}{ Groups } & \multirow{3}{*}{$\begin{array}{c}\text { Total } \\
\text { (n) }\end{array}$} & \multirow[b]{3}{*}{$\mathrm{p}^{a}$} \\
\hline & \multicolumn{2}{|c|}{$\begin{array}{c}\text { Case } \\
(\mathrm{n}=45)\end{array}$} & \multicolumn{2}{|c|}{$\begin{array}{l}\text { Control } \\
(\mathrm{n}=45)\end{array}$} & & \\
\hline & FI & $\%$ & FI & $\%$ & & \\
\hline \multicolumn{7}{|c|}{ Tactile sensitivity } \\
\hline Normal & 42 & 93.3 & 45 & 100 & 87 & 0.241 \\
\hline Disturbed & 3 & 6.7 & - & - & 3 & \\
\hline \multicolumn{7}{|c|}{ Thermal sensitivity } \\
\hline Normal & 37 & 82.2 & 45 & 100 & 82 & 0.005 \\
\hline Disturbed & 8 & 17.8 & - & - & 8 & \\
\hline \multicolumn{7}{|c|}{ Thermal and gustatory sensitivity } \\
\hline Normal & 41 & 91.1 & 45 & 100 & 86 & 0.111 \\
\hline Disturbed & 4 & 8.9 & - & - & 4 & \\
\hline
\end{tabular}

$a$ : two-tailed Fisher's exact test; FI: simple absolute frequency. 
The determination of $M$. leprae DNA in saliva by qPCR returned a positive result in $35.5 \%$ of the 45 subjects; moreover, in five PB cases, saliva qPCR was the only method that returned a positive result. Using conventional PCR, Abdalla et al. (2010) detected 10 (20.8\%) positive tests out of 48 subjects evaluated and Martinez et al. (2011) obtained $51(17.6 \%)$ positive tests out of 290 tests performed by swabbing the oral cavity.

The positive results of the saliva qPCR, especially in PB patients, suggest the possibility of a new site of sample collection. In addition to allowing the detection of DNA in MB and PB subjects, it is important to mention that the collection of saliva is less invasive than the slit- skin smear and could help in situations of uncertainty in the clinical diagnosis. Furthermore, the detection of bacilli in saliva is noteworthy because it suggests that the oral cavity, even in PB subjects, can be a focus of the bacillus that may correlate with the transmission of the disease, as Martinez et al. (2011) speculated.

Altogether, the laboratory tests employed in this study indicated that 25 out of the $45(55.5 \%)$ samples from patients with leprosy had at least one positive result. Although this positivity is relatively low, it is higher than that observed when the three techniques are applied separately. Importantly, the use of the qPCR technique for saliva and smear, together with slit-skin smear bacil-

TABLE II

Relationship between laboratory tests results and operational classification of leprosy

\begin{tabular}{|c|c|c|c|c|c|c|}
\hline \multirow[b]{3}{*}{ Variable } & \multicolumn{4}{|c|}{ Operational classification } & \multirow{3}{*}{$\begin{array}{c}\text { Total } \\
\text { (n) }\end{array}$} & \multirow[b]{3}{*}{$\mathrm{p}^{a}$} \\
\hline & \multicolumn{2}{|c|}{$\begin{array}{l}\text { Paucibacillary } \\
\qquad(\mathrm{n}=19)\end{array}$} & \multicolumn{2}{|c|}{$\begin{array}{l}\text { Multibacillary } \\
\quad(\mathrm{n}=26)\end{array}$} & & \\
\hline & FI & $\%$ & FI & $\%$ & & \\
\hline BI of slit-skin smear & & & & & & $<0.001$ \\
\hline Positive & - & - & 12 & 46.2 & 12 & \\
\hline Negative & 19 & 100 & 14 & 53.8 & 33 & \\
\hline qPCR of slit-skin & & & & & & 0.181 \\
\hline Positive & 3 & 15.8 & 10 & 38.5 & 13 & \\
\hline Negative & 16 & 84.2 & 16 & 61.5 & 32 & \\
\hline $\mathrm{BI}$ of saliva & & & & & & 1 \\
\hline Positive & - & - & 1 & 3.8 & 1 & \\
\hline Negative & 19 & 100 & 25 & 96.2 & 44 & \\
\hline qPCR of saliva & & & & & & 0.756 \\
\hline Positive & 6 & 31.6 & 10 & 38.5 & 16 & \\
\hline Negative & 13 & 68.4 & 16 & 61.5 & 29 & \\
\hline
\end{tabular}

a: two-tailed Fisher's exact test; BI: bacteriological index; FI: simple absolute frequency; qPCR: quantitative polymerase chain reaction.

TABLE III

Relationship between bacilloscopy of slit-skin smear and quantitative polymerase chain reaction (qPCR) of slit-skin smear or saliva

\begin{tabular}{|c|c|c|c|c|c|c|}
\hline \multirow[b]{3}{*}{ Variable } & \multicolumn{6}{|c|}{ Bacteriological index of slit-skin smear } \\
\hline & \multicolumn{2}{|c|}{$\begin{array}{c}\text { Negative } \\
(\mathrm{n}=33)\end{array}$} & \multicolumn{2}{|c|}{$\begin{array}{l}\text { Positive } \\
(\mathrm{n}=12)\end{array}$} & \multirow{2}{*}{$\begin{array}{l}\text { Total } \\
\text { (n) }\end{array}$} & \multirow[b]{2}{*}{$\mathrm{k}$} \\
\hline & FI & $\%$ & FI & $\%$ & & \\
\hline qPCR of saliva & & & & & & 0.18 \\
\hline Positive & 10 & 83.3 & 6 & 50 & 16 & \\
\hline Negative & 23 & 69.7 & 6 & 50 & 29 & \\
\hline qPCR of slit-skin & & & & & & 0.50 \\
\hline Positive & 5 & 15.2 & 8 & 66.7 & 13 & \\
\hline Negative & 28 & 84.8 & 4 & 33.3 & 32 & \\
\hline
\end{tabular}

FI: simple absolute frequency; k: Cohen's kappa test. 
loscopy, resulted in more than twice the number of positive cases than the conventional microscopy test alone. In other words, combining different methodologies may increase the success rate of leprosy diagnosis.

The successful use of qPCR to detect the presence of bacilli in the saliva was an important result because this technique was able to identify bacillus DNA in subjects classified as PB patients (i.e., those who are not positive in the standard slit-skin smear technique). Moreover, the possibility of including samples collected from different sites (slit-skin smear in a skin lesion, slit-skin smear of the ear and saliva collection) in the same tube for DNA extraction, prior to molecular tests, may also serve to increase sensitivity.

Further research should be performed to investigate the viability of bacilli in the saliva of PB subjects. This issue has epidemiological relevance because it raises the possibility of the contribution of PB subjects to disease transmission.

This study was unable to link alterations in oral cavity sensitivity to the presence of M. leprae in the saliva; however, one-third of the enrolled patients with leprosy exhibited abnormalities in oral sensitivity. Thus, further studies evaluating a larger number of patients are required to better understand the pathophysiology of the oral cavity in leprosy.

In conclusion, a multidisciplinary approach, including different health professionals - physicians, nurses, laboratory technicians, dentists and speech language pathologists - may represent an important method contributing to the earlier diagnosis, assessment and rehabilitation of patients with leprosy.

\section{ACKNOWLEDGEMENTS}

To Megumi Sadahiro, from Department of Teaching and Research, André Leturiondo, from Laboratory Management, to Leprosy Ambulatory staff, FUAM and patients, for valuable help during this study.

\section{REFERENCES}

Abdalla LF, Santos JHA, Collado CSC, Cunha MGS, Naveca FG 2010. Mycobacterium leprae in the periodontium, saliva and skin smears of leprosy patients. Rev Odonto Ciênc 25: 148-153.

Banerjee S, Biswas N, Kanti Das N, Sil A, Ghosh P, Raja AHH, Dasgupta S, Datta PK, Bhattacharya B 2011. Diagnosing leprosy: revisiting the role of the slit-skin smear with critical analysis of the applicability of polymerase chain reaction in diagnosis. Int $J$ Dermatol 50: 1522-1527.

Bigom-Taheri J, Mortazavi H, Moshfeghi M, Bakhshi M, Bakhtiari S, Azari-Marhabi S, Alirezaei S 2012. Oro-facial manifestations of 100 leprosy patients. Med Oral Patol Oral Cir Bucal 17: e728732 .

Cohen J 1960. A coefficient of agreement for nominal scales. Educ Psychol Meas 20: 37-46.

D'Abreu PC, Durães SMB, Estrela RR, Baltazar MCNP, Rochael MC 2000. Hanseníase virchowiana diagnosticada através de exame histopatológico de lesão oral em paciente com pênfigo foliáceo. An Bras Dermatol 75: 339-346.

da Costa APF, Nery JAC, Oliveira MLW-del-R, Cuzzi T, Ramos-eSilva M 2003. Oral lesion in leprosy. Indian J Dermatol Venereol Leprol 69: 381-385. de Abreu MAMM, Michalany NS, Weckx LLM, Pimentel DRN, Hirata CHW, Alchorne MMA 2006. A mucosa oral na hanseníase: um estudo clínico e histopatológico. Rev Bras Otorrinolaringol 72: $312-316$

FUAM - Fundação de Dermatologia Tropical e Venereologia Alfredo da Matta 2011. Hanseníase no estado do Amazonas. Situação epidemiológica e operacional da hanseníase no estado do Amazonas - 2011. Boletim Epidemiológico XIII: 5.

Goulart IM, Goulart LR 2008. Leprosy: diagnostic and control challenges for a worldwide disease. Arch Dermatol Res 300: 269290.

Kumar S, Alexander M, Gnanamuthu C 2006. Cranial nerve involvement in patients with leprous neuropathy. Neurol India 54: 283285.

Landis JR, Koch GG 1977. The measurement of observer agreement for categorical data. Biometrics 33: 159-174.

Margarido LC, Rivitti EA 2005. Hanseníase. In R Focaccia (sci. ed.). Tratado de infectologia, 3rd ed., Atheneu, São Paulo, p. 939-972.

Martinez AN, Britto CFP, Nery JAC, Sampaio EP, Jardim MR, Sarno EN, Moraes MO 2006. Evaluation of real-time and conventional PCR targeting complex 85 gene for detection of Mycobacterium leprae DNA in skin biopsy sample from patients diagnosed with leprosy. J Clin Microbiol 44: 3154-3159.

Martinez TS, Figueira MMNR, Costa AV, Gonçalves MA, Goulart LR, Goulart IMB 2011. Oral mucosa as a source for M. leprae infection and transmission and implications of bacterial DNA detection and the immunological status. Clin Microbiol Infect 17: $1653-1658$

MS - Ministério da Saúde 2002. Guia para o controle da hanseníase. Available from: bvsms.saude.gov.br/bvs/publicacoes/guia_de_ hanseniase.pdf.

MS - Ministério da Saúde 2010. Guia de procedimentos técnicos: baciloscopia em hanseníase. Available from: portal.saude.gov.br/ portal/arquivos/pdf/guia_hanseniase_10_0039_m_final.pdf.

Neville B, Damm DD, Allen CM, Bouquot J 2009. Hanseníase. In B Neville, DD Damm, CM Allen, Patologia oral e maxilofacial, 3rd ed., Elsevier, Rio de Janeiro, p. 198-201.

Patrocínio LG, Goulart IM, Goulart LR, Patrocínio JA, Ferreira FR, Fleury RN 2005. Detection of Mycobacterium leprae in nasal mucosa biopsies by the polymerase chain reaction. FEMS Immunol Med Microbiol 44: 311-316.

Phetsuksiri B, Rudeeaneksin J 2006. A simplified reverse transcriptase PCR for rapid detection of Mycobacterium leprae in skin specimens. FEMS Immunol Med Microbiol 48: 319-328.

Pontes ARB, Almeida MGC, Xavier MB, Quaresma JAS, Yassui EA 2008. Detecção do DNA de Mycobacterium leprae em secreção nasal. Rev Bras Enferm 61 (Suppl.): 734-737.

Reichart PA, Srisuwan S, Metah D 1982. Lesions of the facial and trigeminal nerve in leprosy. Int J Oral Surg 11: 14-20.

Scheepers A, Lemmer J, Lownie JF 1993. Oral manifestations of leprosy. Lepr Rev 64: 37-43.

Soni NK, Chatterji P 1981. Disturbance of taste in leprosy. J Laryngol Otol 95: 717-720.

Villar VM, Furia CLB, Mello Jr EJF 2004. Disfagia orofaríngea em indivíduos portadores de hanseníase. Rev CEFAC 6: 151-157.

Wani AA, Gupta V, Jan N 2009. A clinical study of the cranial nerve involvement in leprosy. Dermatol Online J 5: 3.

WHO - World Health Organization 2012. Global leprosy situation. Wkly Epidemiol Rec 34: 317-328. 